Endocrinol. Japon. 1961, 8 (4), 279 287

\title{
STUDIES ON THE PROLACTIN-LIKE SUBSTANCE IN HUMAN PLAGENTA II
}

\author{
YOSOJI ITO AND KYOKO HIGASHI
}

\author{
Department of Physiological Chemistry, Faculty of Pharmaceutical \\ Sciences, University of Tokyo, Tokyo
}

The existence of prolactin-like substance in the animal placentas of various species has been reported by some authors (Ehrhardt, 1936; Ray et al., 1955), but only a few informations have been obtained on the human placenta. Ehrhardt (1936) found that a prolactin-like substance was contained in the human and animal placentas and that in the human placenta this substance was mainly contained in the early stage of the pregnancy. Fujii (1938) has reported, however, that the human placenta does not contain such a substance.

In the previous publication, the authors (Ito and Higashi, 1953) have reported that a material obtained from the human placenta by the "acid-acetone" method of Lyons (1936-37) possesses the activities of proliferating the mucous membrane of the crop-glands and producing the crop milk in pigeons. This method, however, is not always suitable for the extraction of the active substance from the human placenta because of its low yield.

The present paper describes an improved method for the preparation of the prolactin-like substance in human placenta. A precipitate obtained by this method causes a marked proliferation of the mucous membrane of the crop-glands, a secretion of the crop milk, and an increase of the number of the fatty granules in the crop milk of pigeons.

These activities are similar to those of the lactogenic hormone of anterior pituitary.

\section{MATERIALS AND METHODS}

The human placenta of normal delivery was used as the starting material. The placenta was frozen with dry ice to avoid the denaturation or autolysis and was carried back to the laboratory.

The biological activity of the prolactin-like substance in the human placenta was assayed by the observation of the appearance of the fatty granules in the crop milk and the proliferation of the mucous membrane of the crop-glands in pigeons. Namely, the "local" intradermal method for the assay of prolactin (Lyons and Page, 1935; Lyons, 1936-37) was employed. The male and female pigeons having never nested and weighing about $300 \mathrm{~g}$ were used. Forty eight hrs. after a single injection with a test solution over the crop-glands, the pigeons were sacrificed and the crop-glands were removed, weighed and provided for the histological studies. The fatty

Received for publication March 29, 1961. 
granules in the crop milk were examined by staining with the solutions of saturated Sudan III in $70 \%$ ethanol and hematoxylin, and the tissues of the crop-glands were prepared with the usual hematoxylin-eosin staining method.

\section{EXPERIMENTS AND RESULTS}

\section{1) Separation of the $p H$ 5.4-precipitate from the human placenta}

The human placenta was minced and placed immediately in 1.5 vols. of weekly alkaline water $(\mathrm{pH} 8.6 \sim 8.8)$. Extraction was carried out for $6 \mathrm{hrs}$. at $0 \sim 5^{\circ} \mathrm{C}$ under constant stirring. The residual tissue was extracted twice with 2 vols. of water. The solution was adjusted to $\mathrm{pH} 5.4$ with $N$ HCl. After being stood over night in an ice box, the precipitate was separated by centrifugation and lyophylized.

2) Freezing followed by thawing and filtration in acid or alkaline medium

The $\mathrm{pH}$ 5.4-precipitate was dissolved in the 100 vols. of water at $\mathrm{pH} 1.8 \sim 2.0$ or $\mathrm{pH} 8.6 \sim 8.8$. The $\mathrm{pH}$ of the solution was maintained to be constant with $N \mathrm{HCl}$ or $N \mathrm{NaOH}$. The turbid solutions were frozen in refrigerator, followed by thawing at $5 \sim 10^{\circ} \mathrm{C}$, being wrapped up the frozen mass in a gauze and stiffed with absorbent cotton and each of the filtrates was lyophylized.

$\begin{array}{cccc} & \text { Yield } & \begin{array}{c}\text { The colour of } \\ \text { the solutions } \\ \text { reddish brown } \\ \text { (turbid) }\end{array} & \begin{array}{c}\text { The colour of the } \\ \text { lyophylized solutions }\end{array} \\ \begin{array}{c}\mathrm{pH} \mathrm{8.6 \sim 8.8} \\ \text { filtrate }\end{array} & 60.4 \% & \begin{array}{c}\text { brownish yellow } \\ \text { (clear) }\end{array} & \text { gray } \\ \begin{array}{c}\mathrm{pH} \mathrm{1.8 \sim 2.0} \\ \text { filtrate }\end{array} & 64.0 \% & \begin{array}{c}\text { light red } \\ \text { (n) }\end{array} & \text { grate }\end{array}$

Of each fraction the biological activity was assayed. The results are shown in Table 1 .

As shown in Table 1, the proliferation of the stratum epithelium and the cells of the germinativum was remarkable in the pigeons administered with the acid filtrate. The amounts of the crop milk and the fatty granules in the crop milk in the group injected with the acid filtrate were larger than those with the alkaline filtrate. Moreover, this tendency was similarly observed on the increase of the crop-gland weight. From these results, it was supposed that the acid filtrate is more effective than the alkaline filtrate.

3) Fractional precipitation with ammonium sulfate of the acid filtrate

The yield of the precipitate at the concentration of $10 \%$ of ammonium sulfate (the $10 \%$-precipitate) was $38.5 \%$, and the yields of the precipitates at other concentrations were low (Table 2). These fractions were divided into 3 groups; the $<10 \%-$, $10 \sim 25 \%$ - and $>25 \%$-precipitate, and the biological activity of each fraction was assayed. The results are shown in Table 3.

The responses of the increase of the amounts of the crop milk and of the granules of the fat in the crop milk were striking in the groups to which the $<10 \%$ - or $10 \sim 25 \%$-precipitate was injected. The same tendency was also seen on the increase of crop-gland weight. In the histological observation, the proliferation was observed in a limited area of the stratum epithelium in the group 


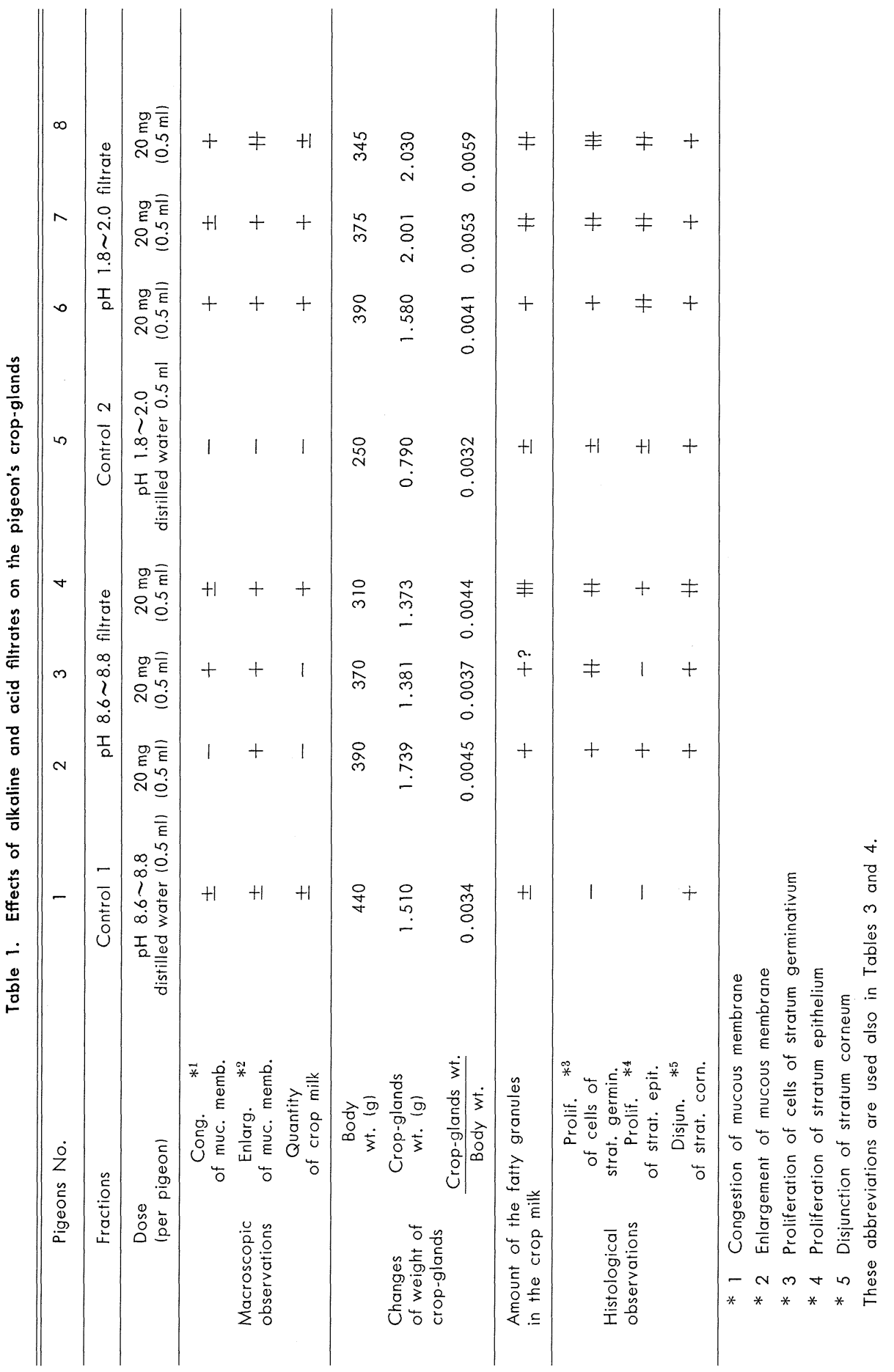


Table 2.

\begin{tabular}{ccc}
\hline Fractions & Dry weight $(g)$ & Yield $(\%)$ \\
\hline$<10 \%$-precipitate & 0.592 & 38.5 \\
$10 \sim 20 \%$-precipitate & 0.104 & 7.0 \\
$20 \sim 25 \%$-precipitate & 0.020 & 1.3 \\
$25 \sim 30 \%$-precipitate & 0.028 & 1.9 \\
$>30 \%$-precipitate & 0.058 & 3.9 \\
\hline
\end{tabular}

injected with the $<10 \%$-precipitate, but in the group injected with the $10 \sim 25 \%$ precipitate the proliferation in whole area of the stratum epithelium and the cells of the stratum germinativum was shown remarkably. The proliferation of the stratum epithelium and the cells of the stratum germinativum of the group injected with the $>25 \%$-precipitate was inferior to those of the group injected with the $10 \sim 25 \%$-precipitate. It may be obvious from these results that the active principle in the $\mathrm{pH}$ 5.4-precipitate is concentrated in the $10 \sim 25 \%$-precipitate.

4) The separation of the $>25 \%-\left(\mathrm{NH}_{4}\right)_{2} \mathrm{SO}_{4}$-precipitate from the $\mathrm{pH}$ 5.4-supernatant

By the previous experiments, it was proved that the $10 \sim 25 \%$-precipitate in the $\mathrm{pH}$ 5.4-precipitate was effective. Therefore, the $>25 \%$-precipitate was separated from the $\mathrm{pH}$ 5.4-supernatant by the fractional precipitation with ammonium sulfate, and the activity of this fraction was assayed.

Comparing the activity of the $10 \sim 25 \%-\left(\mathrm{NH}_{4}\right)_{2} \mathrm{SO}_{4}$-precipitate from the $\mathrm{pH}$ 5.4precipitate to that of the $>25 \%$ - $\left(\mathrm{NH}_{4}\right)_{2} \mathrm{SO}_{4}$-precipitate from the $\mathrm{pH}$ 5.4-supernatant, the former was generally stronger than the latter. The secretion of crop milk and increase of the number of the fatty granules in the crop milk in the group injected with the former were stronger than those in the group injected with the latter. But the proliferation of the stratum epithelium and of the cells of the stratum germinativum was alike as that of the latter (Table 4 and Fig. 1).

\section{DISCUSSION}

The authors (Ito and Higashi, 1953) isolated the material from the human placenta by the "acid-acetone" method of Lyons which possesses the activities similar to the anterior pituitary lactogenic hormone. But, this preparative method is not suitable in this case, since the concentration of the acetone added is so high that it consumes very long time to obtain the complete precipitation. A part of the active protein was denatured and the yield was considerably low.

In order to overcome these difficulties, the following methods were applied to the extraction of the active protein; the extraction with glacial acetic acid (Payne et al., 1950), with a mixture of chloroform and water (Schwenk et al., 1943), with $70 \%$ acetone following fixation of tissue with picric acid (Dudlay, 1924), and with alkaline distilled water of $\mathrm{pH} 8.6 \sim 8.8$. Considering the results of these experiments, it was supposed that the extraction with alkaline water of $\mathrm{pH} 8.6 \sim$ 8.8 followed by the fractional precipitation with ammonium sulfate was the most suitable method for the extraction of the substance in the human placenta.

The process of successive freezing and thawing permitted to obtain a clear 


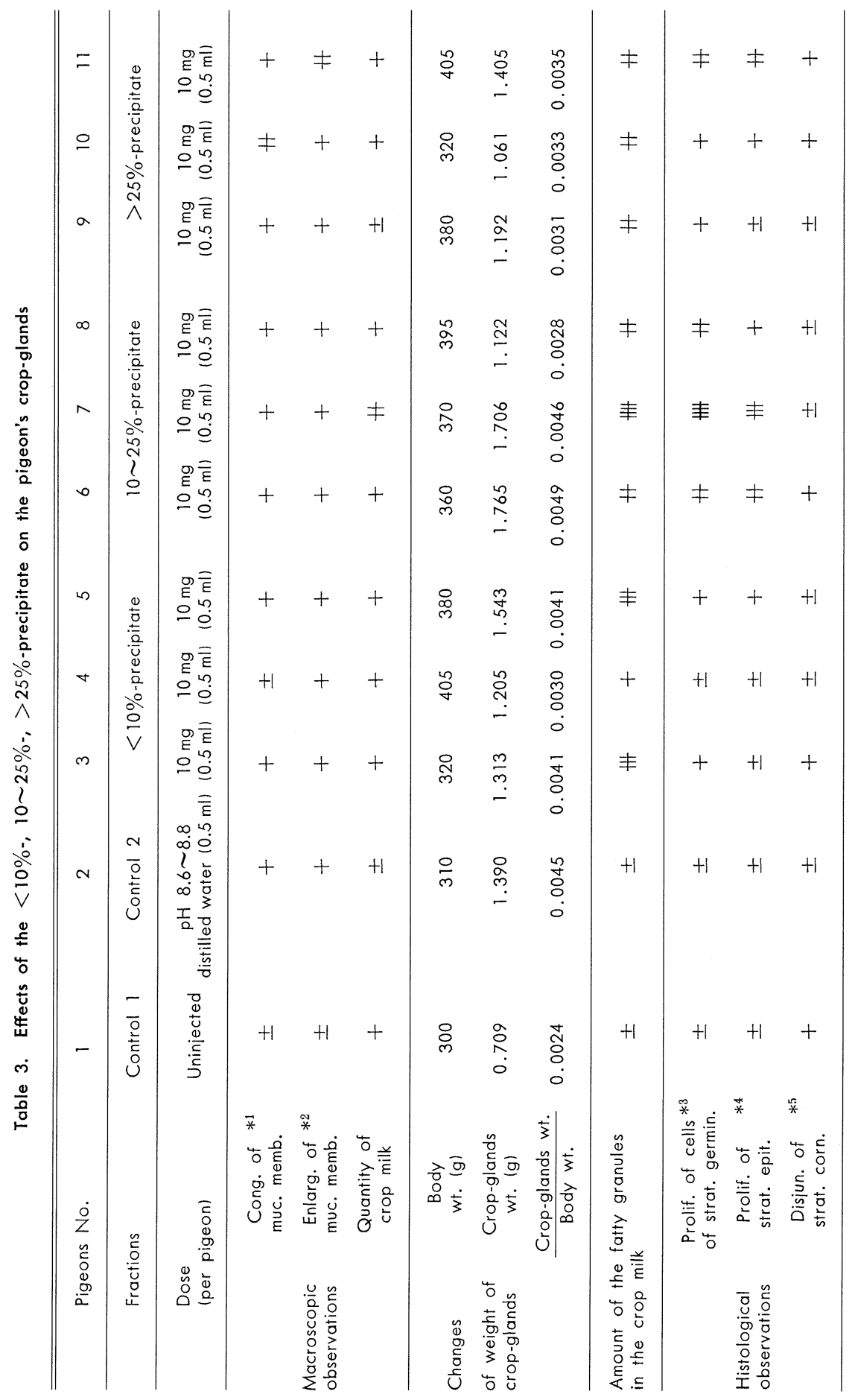


Fig. 1. The histological pictures of the crop-glands of pigeons

A and B : The crop-gland of pigeons at $48 \mathrm{hrs}$. after a single injection of the extract of alkaline water of $\mathrm{pH} 8.6 \sim 8.8$

C: The crop-gland of pigeons at $48 \mathrm{hrs}$. after a single injection of $10 \mathrm{mg}$ of the $10 \sim 25 \%$ precipitate from the $\mathrm{pH}$ 5.4-precipitate (Table 4). The proliferation of the cells of the stratum germinativum is remarkable.

D: The crop-gland of pigeons at $48 \mathrm{hrs}$. after a single injection of $10 \mathrm{mg}$ of the $10 \sim 25 \%$ precipitate from the $\mathrm{pH}$ 5.4-pecipitate (Table 4). The disiunction of the stratum corneum and the proliferation of the cells of the stratum germinativum is remarkable.

E: The crop-gland of pigeons at $48 \mathrm{hrs}$. after a single injection of $10 \mathrm{mg}$ of the $10 \sim 25 \%$ precipitate from the $\mathrm{pH}$ 5.4-precipitate (Table 4). The proliferation of the stratum epithelium is remarkable.

$\mathrm{G}$ and $\mathrm{H}$ : The crop-gland of pigeons at $48 \mathrm{hrs}$. after a single injection of $10 \mathrm{mg}$ of the 25\%-precipitate from the $\mathrm{pH} 5.4$-supernatant (Table 4). The proliferation of the stratum epithelium alone is remarkable.

and decolorized solution. This filtrate is adjusted to $\mathrm{pH} 8.6 \sim 8.8$ with $\mathrm{N} \mathrm{NaOH}$, and after the centrifugation, the supernatant was submitted to the fractional precipitation with ammonium sulfate. The each fraction was assayed by the pigeon's crop-gland method and the precipitate at concentrations of $10 \sim 25 \%$ of ammonium sulfate from the $\mathrm{pH}$ 5.4-precipitate was shown to be effective (Table 3).

The assay method employed is the "local" method introduced by Lyons and Page (1935). In this assay, it must be payed attention to use the young pigeons weighing about $300 \mathrm{~g}$, which has never nested. Because, the nesting pigeons cause proliferation of the mucous membrane of the crop-gland and production of the fatty granules in the cells of the stratum epithelium of the crop-gland without any treatment, and this condition continues until the breeding settles.

In these experiments, the histological changes of the tissue of the crop-gland and the increases of number of the granules of the fat in the gland were employed mainly as the indices of the activity instead of the increase of the weight, because a large amount of the material was required to induce the significant change in the weight of the gland. The histological changes do not coincide with the change in the weight of the crop-gland; for instance, in the response of the weight of the crop-glands, the group injected with the $<10 \%$-precipitate was stronger than the group with the $>25 \%$-precipitate, but in the histological response the reverse is the case (Table 3). This phenomenone may be caused by the fact that the proliferation of the stratum epithelium is remarkable in the group injected with the $10 \sim 25 \%$-precipitate from the $\mathrm{pH}$ 5.4-precipitate, but in the group injected with the $<10 \%$-precipitate the proliferation occours rather on the tissue of the stratum proprium (Tunica propria mucosae).

As shown in Table 4 and Figure 1, the injection of the $>25 \%$-precipitate from the $\mathrm{pH}$ 5.4-supernatant also produces proliferation of the mucous membrane of the cropgland. In this case, however, the proliferation of the cells of the stratum germinativum is different from that produced by the $10 \sim 25 \%$-precipitate from the $\mathrm{pH}$ 5.4-precipitate, and also the amount of crop milk is small. From these reasons, the $10 \sim 25 \%$-precipitate from the $\mathrm{pH} 5.4$-precipitate and $>25 \%$-precipitate from 

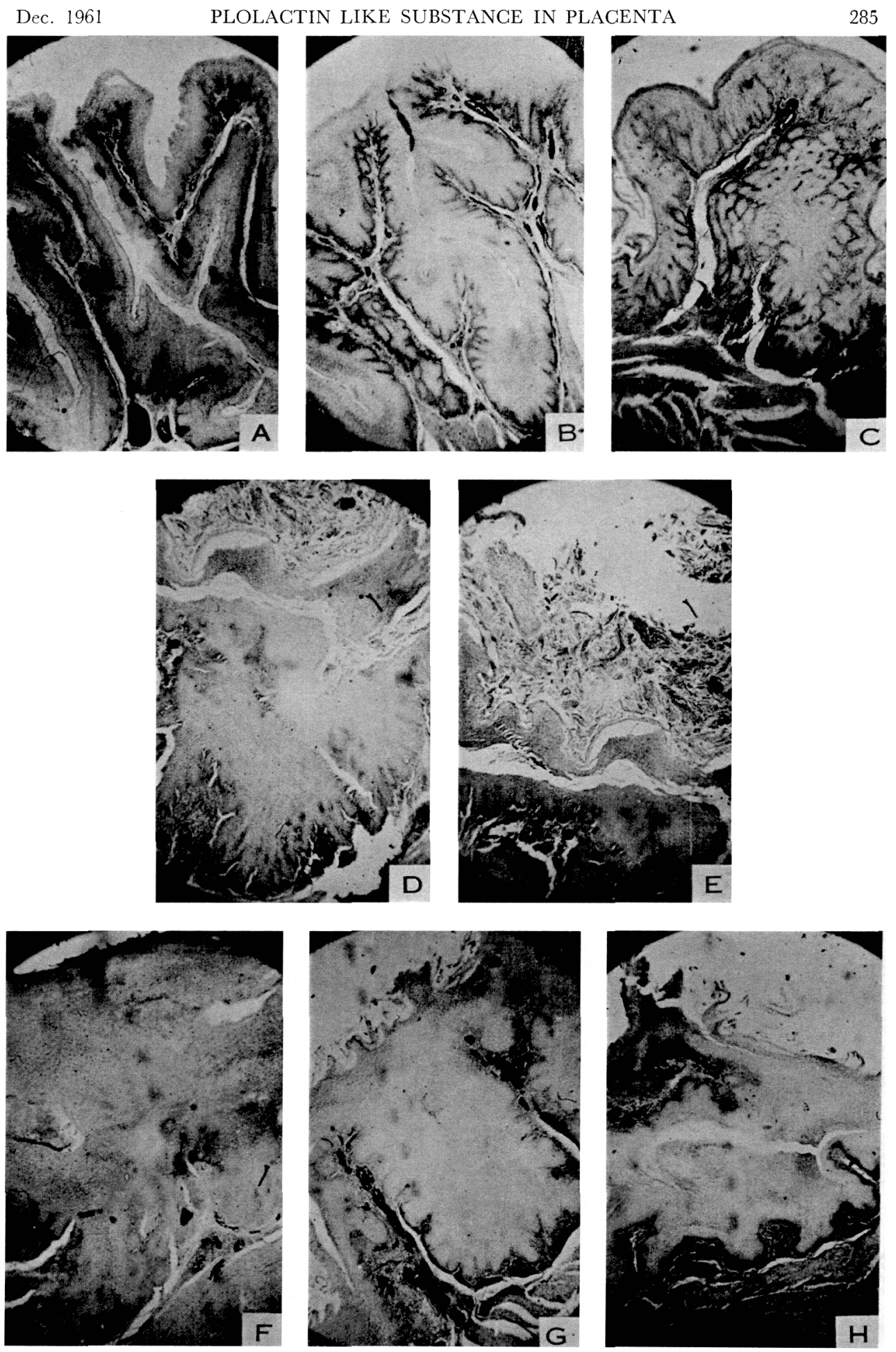


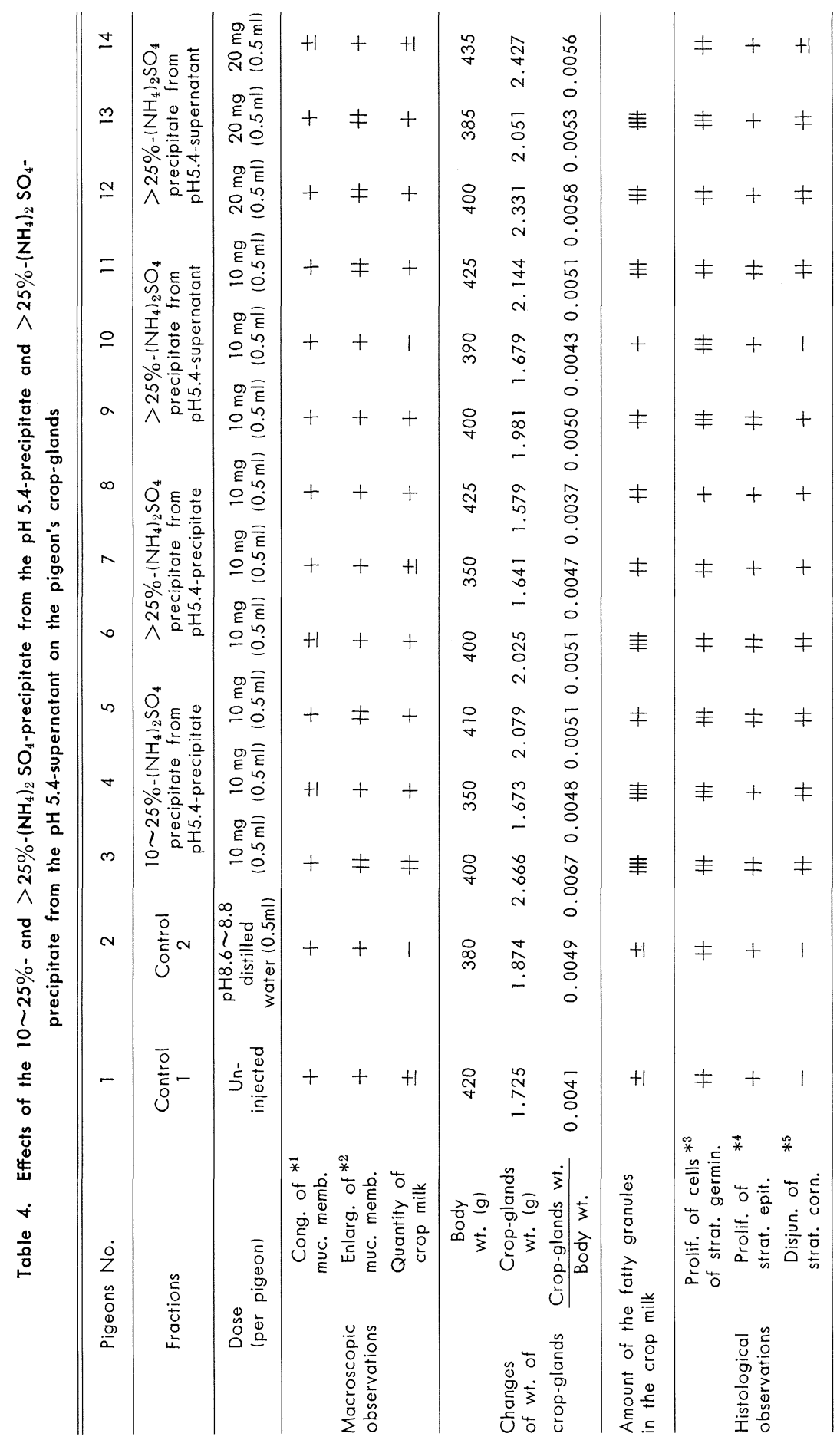


the $\mathrm{pH}$ 5.4-supernatant may be quite different.

It is assumed, therefore, that the factor which acts on the secretion of the crop milk and which acts on the proliferation of the crop-gland tissues may be different and might be separated by the further purification process.

\section{SUMMARY}

A prolactin-like substance was isolated from the human placenta by the method of extraction with alkaline water of $\mathrm{pH} 8.6 \sim 8.8$ and the fractional precipitation with ammonium sulfate. The substance possesses the crop-glandstimulating activity similar to the anterior pituitary lactogenic hormone. The activity is concentrated in a precipitate at the concentration of $10 \sim 25 \%$ of ammonium sulfate from the $\mathrm{pH}$ 5.4-precipitate. This fraction causes proliferation of the mucous membrane of the crop-gland, production of the crop milk and increase of the granules of the fat in the crop milk.

\section{REFERENCES}

Dudlay, H.W. (1924). Biochem. J. 18, 665.

Ehrhardt, K. (1936). Münch. med. Wochschr. 29, 1163.

Fujii, K. (1938). J. Japan. Obstet. Gynecol. 33, 1. (In Japanese)

Ito, Y. and K. Higashi (1953). J. Pharm. Soc. Japan. 73, 89. (In Japanese)

Lyons, W.R. and E. Page (1935). Proc. Soc. Exptl. Biol. Med. 32, 1049.

Lyons, W.R. (1936-37). Ibid. 35, 645.

Payne, R.W., N.S. Raben and E.B. Astwood (1950). J. Biol. Chem. 187, 719.

Ray, E.W., S.G. Averill, W.R. Lyons and R.E. Johnson (1955). Endocrinology 56, 4, 359.

Schwenk, E., G.A. Fisher and S. Tolkshorf (1943). J. Biol. Chem. 147, 535. 